\title{
De un bello pensamiento filosófico a una acción específica: la paz en las memorias de Ángel Cuervo y Tomás Cuenca sobre la guerra de 1859-1862*
}

Recibido: 17/07/2020 | Revisado: 16/10/2020 | Aceptado: 23/10/2020

DOI: 10.17230/co-herencia.18.34.12

\section{Patricia Cardona Z.** \\ azuluaga@eafit.edu.co}

\begin{abstract}
Resumen Este artículo analiza en dos escritos en primera persona (memorias), de Ángel Cuervo y Tomás Cuenca, la idea de paz en la Guerra por las Soberanías (1859. 1862), que enfrentó a las fuerzas oficialistas del gobierno conservador presidido por Mariano Ospina con las de los liberales lideradas por Tomás Cipriano de Mosquera. A partir del análisis de ambos textos vistos en correlación con el contexto y con documentación de época de diversa índole, se estudian algunos avenimientos y de qué modo se incorpora el derecho de gentes y los mecanismos de contención de la guerra que desembocó en la promulgación del artículo 91 de la Constitución de 1863.
\end{abstract}

\section{Palabras clave:}

Guerra, paz, derecho de gentes, historia de Colombia.

\section{From Beautiful Philosophical Thought to Specific Actions: Peace in the Memoirs of Ángel Cuervo and Tomás Cuenca on the War of 1859-1862}

\footnotetext{
Abstract This article looks at two first-person memoirs by Ángel Cuervo and Tomás Cuenca, analyzing the idea of peace during the War for Sovereignty (1859-1862), in which
}

* Texto derivado de la investigación Lenguajes $y$ estrategias de paz, Colombia siglo xIx, con el apoyo de la Vicerrectoría de Descubrimiento y Creación de la Universidad EAFIT y radicada con el número 881.000001 .

** Profesora investigadora de la Universidad EAFIT, Medellín-Colombia. ORCID: 0000-00020182-5595. 
the ruling forces of the conservative government led by Mariano Ospina confronted those of the Liberals led by Tomás Cipriano de Mosquera. Based on the analysis of both texts seen in correlation with the context and with various types of period documentation, some agreements are studied in addition to how the law of nations and the containment mechanisms of the war led to the promulgation of Article 91 of the Constitution of 1863.

\section{Keywords:}

War, peace, people's rights, history of Colombia.

En Colombia el siglo XIX se ha visto, por lo general, como un entramado de guerras sucesivas que dificultaron la formación del Estado y retrasaron la construcción nacional. La bibliografía sobre las guerras en Colombia es extensa y rica, no solo por su variedad teórica, metodológica y su aporte empírico, sino además porque es un campo de investigación consolidado en el país. No obstante, la paz apenas se vislumbra como un terreno de investigación, que paulatinamente podrá desplazar la centralidad de la guerra, la reconstrucción detallada de acontecimientos bélicos y las dimensiones socioeconómicas. De hecho, desde hace unos años se ha intentado ensanchar la comprensión de la guerra con la inclusión de las estrategias de negociación que hicieron posible la terminación de los levantamientos armados, así como la preparación y disposición social para la reconciliación y la integración de quienes hicieron uso de las armas (Aguilera, 2012; Orozco, 2006; Uribe, 2003; Uribe y López, 2006, 2008); la paz, sus nominaciones, palabras y estrategias cuentan ya con una dinámica propia, a fin de comprender los mecanismos que ayudan a superar los conflictos, como las formas de reinserción y las políticas de memoria y olvido indispensables para redefinir el pacto social (Guerrero, 2016, 2017; Garrido et al., 2018; Karl, 2018; Rivera, 2019).

No obstante, la paz y los ideales erigidos alrededor de esta noción están entretejidos con los discursos bélicos y los eventos militares que sacudieron al país a lo largo del siglo XIX. Es por ello por lo que este trabajo se propone analizar a partir de escritos en primera persona algunos asuntos en torno a la idea de paz en el contexto de la Guerra por las Soberanías (1859-1862), que enfrentó a las fuerzas oficialistas 
del gobierno conservador de Mariano Ospina Rodríguez (1805-1885) con las de los liberales lideradas por Tomás Cipriano de Mosquera (1798-1878), quienes se oponían al gobierno partidista y a los embates centralizantes que atentaban contra el principio federativo de la Constitución de 1858 que, en su criterio, conculcaba Ospina.

El estudio de textos en primera persona como los diarios, las memorias y los apuntes obliga a definir sus alcances y límites fácticos y ficticios, exige al historiador indagar en su naturaleza, profundizar en sus condiciones de enunciación, conocer la dislocación temporal entre el pasado que testimonian y el presente del testimonio. La subjetividad del recuerdo se contrasta con la facticidad que aporta el conocimiento histórico; el encuentro entre el recuerdo y la historia, como disciplina académica, ayuda en la tarea de integrar lo individual en las sociabilidades de una época, observar lo particular contrapuesto con lo general, cotejar datos y precisar hechos. Esas operaciones permiten perfilar mejor el hecho histórico, identificar los contenidos ficticios o tergiversados, y no por un prurito de hallar el error; antes bien, las ficciones, las tergiversaciones, las ilusiones, son aspectos que pueden ser estudiados y comprendidos por los historiadores, bien sea para ubicarlos en el cauce de las "mentalidades", el espíritu de época, o en el de los ideales compartidos.

El recorrido será el siguiente: en un primer momento ubicaremos la época en la que se centra este artículo, y luego nos ocuparemos de las memorias que dejaron los testigos de los hechos. En un segundo momento procuraremos hacer un seguimiento a la noción de víctima tal y como se comprendía en la Guerra por las Soberanías. En la tercera parte intentaremos hacer una breve descripción de cómo los autores de las memorias que nos ocupan, Ángel Cuervo y Tomás Cuenca, definen y entienden la paz y anuncian la preocupación por el derecho de gentes y la contención de la guerra incorporados en la Constitución de 1863. 


\section{La situación de la guerra y la definición concreta de la paz}

La guerra de 1859 tuvo una gran significación en la segunda mitad del siglo XIX, toda vez que vencieron los rebeldes, en su mayoría liberales radicales que asumieron la tarea de defender la Constitución política de 1858 que daba forma legal a una organización política confederada, formada por nueve Estados soberanos, establecidos así entre 1857 y 1858, unidos por un gobierno central con muy poca injerencia en los asuntos internos de los Estados. Se trató entonces de una guerra en la que se disputó la soberanía entre los Estados soberanos y el Estado central, de la que participaron activamente las burocracias políticas y letradas que tomaron las armas para defender la Constitución de 1858 o para defender el celo unitarista del gobierno de la Unión, lo que condujo a la separación del Estado Soberano del Cauca de la Confederación. Por ello, la guerra adquirió una connotación internacional que la hizo aún más sangrienta, compleja y sui generis. Los ejércitos gobiernistas y los alzados en armas se lanzaron a una guerra sin cuartel con batallas cruentas y prácticas atroces en el tratamiento de heridos, reos, desertores y población no involucrada en el conflicto. Sin embargo, la ausencia de planificación estratégica por parte del mando militar del Gobierno, así como la relativa ventaja en el número de hombres llevó a que, por única vez, los rebeldes ganaran la guerra. Tomás Cipriano de Mosquera triunfó, y con él el proyecto liberal radical que marcó los rumbos del país desde 1862 hasta 1885, mediante la Constitución política de 1863 y la reforma educativa de 1870 , que reglamentaban y legitimaban un régimen federal de libertades individuales (de conciencia, de credo, de imprenta, de industria), que buscaba la subordinación de la Iglesia al Estado y la formación de una ciudadanía racional, expresión máxima del proyecto civilizatorio y modernizante del liberalismo colombiano de la época, pero con un poder ejecutivo débil, elegible cada dos años, incapaz de contener y negociar con los enormes fueros regionales.

La complejidad de esta guerra, así como la incertidumbre sobre quién vencería y cuándo, llevó a los combatientes de ambos bandos a desplegar medidas para regularizar y normalizar las acciones bélicas. 
Tomás Cipriano de Mosquera, general en jefe de las fuerzas rebeldes liberales, lideró pactos como la Exponsión de Manizales (29 de agosto de 1860) y el Armisticio de Chaguaní (3 de marzo de 1861) que, de forma paralela a las acciones bélicas, intentaban menguar los efectos letales de la confrontación. No podría decirse que la actitud de Mosquera coincidía con una preocupación desinteresada por el derecho de gentes, que conocía a través de la lectura de sus teóricos más representativos: Emerich de Vattel y Andrés Bello (Posada Gutiérrez, 1975, p. 246). ${ }^{1}$ El propósito de Mosquera no era solo atenuar y poner límites a las acciones armadas; la invocación del derecho de gentes le permitía sacar ventaja política, reorganizar la estrategia militar y paliar los efectos inmediatos de la guerra y, a largo plazo, garantizar una posición ventajosa para sus seguidores, que ayudara a la estabilidad política y a la armonía social, expresiones vinculadas con la paz y su correlato moderno de progreso y civilización.

La paz no se presentaba como una noción autónoma y autorreferencial; estaba fundida con el lenguaje bélico y con las estrategias para limitar sus acciones. Sus formas se amalgamaban en función de la guerra y de las disposiciones políticas y sociales para evitar nuevos choques, de allí que estuviera ligada a acciones objetivas, detalladas en el tiempo y el espacio. La Exponsión de Manizales, por ejemplo, refería una negociación entre los jefes militares de los ejércitos, quienes buscaban superar temporalmente los excesos de la guerra y ganar tiempo para atender a los heridos, permitir el retiro de las tropas e intercambiar prisioneros. Las exponsiones se acotaban temporalmente, y sus efectos no alcanzaban el cese de compromisos de orden jurídico para fundamentar la paz o crear normas y contenciones más allá del espacio delimitado en el que tenían lugar. Los armisticios, en cambio, se establecían como cese temporal de las hostilidades para sentar las bases jurídicas para la finalización de la guerra y la implementación de avenimientos: "[...] conseguir la paz de

Mosquera conocía los textos de Emerich de Vattel y de Andrés Bello. Existe una referencia conocida a estos dos autores; se trata de la justificación que hizo Mosquera del fusilamiento de Salvador Córdova, Supremo de Antioquia, el 8 de julio de 1841, indicando que para Vattel "solo una necesidad extrema puede justificar una acción tan terrible" y que, según Bello "en su Derecho de Gentes", cuando la seguridad propia está en riesgo, "es permitido quitar la vida al enemigo" (citado en Posada Gutiérrez, 1975, p. 246). 
la confederación por medio de un acuerdo amistoso", como quedó estipulado en el Armisticio de Chaguaní (Actos oficiales, 1862, p. 65).

El alborozo de Tomás Cipriano de Mosquera con el Armisticio de Chaguaní surgía de que este era un reconocimiento explícito del gobierno central a los alzados en armas como "beligerantes legítimos" y resaltaba su posición como parte política legítima de la contienda. Gracias a este acuerdo, decía Mosquera, "no hay rebeldes en el lenguaje oficial, como no los ha habido nunca en la realidad" (Actos oficiales, 1862, pp. 66-67). Empero, la Exponsión de Manizales y el Armisticio de Chaguaní fueron rechazados por el presidente Mariano Ospina Rodríguez (1805-1885). Ese rechazo implicaba también el desconocimiento de los rebeldes como interlocutores legítimos, la criminalización de sus acciones y la negativa a concederles indultos y amnistías que, según Ospina, estimulaban "los actos contra la seguridad y el orden público" que, en el mundo civilizado, aducía el presidente, "están sujetos a las penas más graves" (Ospina, 1861, p. 11).

Carl Schmitt circunscribe la paz a emplazamientos concretos: el Estado, el país, el imperio, sustrayéndole un contenido general, normativo o meramente retórico (2005, p. 39). En la vida política del siglo XIX la paz se materializaba en formas concretas que afectaban de manera directa la vida social y política. ${ }^{2}$ Sus efectos jurídicos rebasaban la terminación de la guerra, la paz abarcaba discursos y prácticas que pretendían normalizar las relaciones sociales, atenuar los efectos de las luchas armadas y generar las disposiciones necesarias para evitar nuevas contiendas. La paz entonces no era la ausencia total de la guerra; ella funcionaba como un conjunto de prácticas -verbigracia, las exponsiones y los armisticios, las treguas, las declaratorias de neutralidad o los indultos- que limitaban las acciones militares durante la guerra, y planteaban las disposiciones jurídicas para reincorporar políticamente a los combatientes, resarcir los da-

Señalemos que hay una tradición legal sobre la guerra justa en el mundo hispánico, uno de cuyos representantes más notables fue Francisco de Vitoria y la escuela de Salamanca. La guerra constituía una preocupación política para los hombres del siglo XVI. En general, Vitoria y la escuela de Salamanca definen la guerra como un mal necesario para castigar injurias graves, con el menor daño posible. La guerra no solo se conceptúa como un asunto moral, es también un hecho jurídico en el que hay actos ilícitos que deben ser evitados. Véase Francisco de Vitoria (2008). 
ños ocasionados y limitar el deseo de venganza frente a los atropellos cometidos y garantizar el logro de la armonía social indispensable para la civilización y el progreso.

\section{Memorias de la guerra}

En este escrito, y para centrarnos en la guerra de 1860, recurriremos a dos memorias: las de Ángel Cuervo -Cómo se evapora un ejército-, escritas a finales del siglo XIX con una distancia temporal de unos treinta años entre los hechos y su relato, y las de Tomás Cuenca -Notas sobre la campaña de 1861-, quien estuvo en las filas federalistas al mando del general Mosquera. Tomás Cuenca y Ángel Cuervo fueron testigos directos y actores de las operaciones bélicas y políticas. A diferencia de miles de hombres que fueron reclutados de manera forzada, Cuenca y Cuervo asumieron voluntariamente las armas para defender la causa con la que simpatizaban; además, fueron personajes políticos miembros de los círculos letrados cercanos al poder, con "autoridad" moral y política para entregar su versión a la opinión pública, a un lector "ideal" que buscaban acercar a su causa.

Ángel Cuervo (1838-1896) y Tomás Cuenca (1838-1870) gozaban de reconocimiento y estimación política en su época. Ambos abrazaron la vida militar en bandos enfrentados, Cuenca luchando por la causa liberal y Cuervo en las filas gobiernistas de la Confederación granadina. Ángel Cuervo era miembro de una prominente familia bogotana de su tiempo, Rufino su padre (1801-1853) había sido uno de los fundadores del Partido Conservador. Cuervo defendió con ahínco al gobierno constitucional, pero ello no obnubiló su capacidad crítica a la hora de analizar la escasa preparación y organización del ejército confederado para enfrentar al enemigo.

Tomás Cuenca fue uno de los más importantes periodistas liberales de su tiempo, afecto a la causa radical que defendió y promovió desde distintos frentes; en sus memorias, Ángel Cuervo lo recordaba como un hombre cuyos "odios políticos solían ofuscar la claridad de su inteligencia” (1900, p. 87). Cuenca fue redactor y colaborador de varios periódicos, sus traducciones se publicaron en la Escuela Normal -periódico oficial de instrucción pública de los 
radicales-, fue ministro de Hacienda a los 21 años, y murió a los 32 años en Tena. A su muerte dejó sus Notas de campaña, editadas por Jorge Roa en 1893.

Entre las características generales de las memorias, pueden señalarse varias, tales como su pretensión de verdad, plasmada en el uso de la descripción como forma de objetivar y figurar con exactitud los hechos. En correspondencia con la pretensión de verdad, se comprendía el pasado como un hecho dado que podía ser fielmente "reconstruido" mediante la narración; la indagación no era una operación que estuviera en su núcleo, ya que el pasado aún no era comprendido como objeto de conocimiento, era una realidad que podía restablecerse en su plenitud mediante el relato. Así pues, su idea de verdad estaba erigida sobre el presupuesto de que era coincidente con la realidad que se había vivido.

A su vez, las memorias recurrían a estrategias retóricas para validar el relato como verdadero: las precisiones geográficas, las descripciones de personajes, eventos y batallas, la incorporación y apelación permanente a documentos consultados (la más de las veces sin referenciar) reforzaban su condición de testimonio fiel, sin mediación alguna entre el hecho y su narrador: Ángel Cuervo afirmaba que su libro era "fruto de los recuerdos personales de aquella época aciaga, coordinados a la luz de documentos contemporáneos". Así, del "tesoro de sus recuerdos" emergía la idea de que era este un testimonio veraz que narraba los hechos, tal cual se habían presenciado desde una posición que, aunque sencilla, lo había puesto en el epicentro de las acciones con "el modesto grado que tenía en el ejército legítimo" (Cuervo, 1900, p. VIII).

Las memorias y su corolario fáctico proscribían los artificios estéticos ("la verdad no necesita artilugios poéticos"; Kosselleck, 2004, p. 48), la ornamentación quedaba limitada al terreno de la res fictae. Para enfatizar en su contenido verdadero, la referencia a detalles, precisiones y descripciones "exactas" fortalecían la idea de inmediatez entre el hecho y su narrador. Según lo refiere Ángel Cuervo al contar los hechos de que había sido testigo, su lenguaje era "llano y liso, como conversación familiar y sin los atavíos que la historia pide para las obras científicas” (1900, p. VIII). Fundadas en 
la fidelidad del recuerdo, las memorias no eran Historia, sino, por así decirlo, un acopio de sucesos exactos centrados en una persona y en un acontecimiento, que no tenían el carácter sintético y erudito que se le empezaba a reclamar a la Historia.

Situados en el centro de la narración, los autores presentan sus recuerdos a modo de testimonio fiel; Cuervo invoca su "rectitud y veracidad" para asegurarle al lector que "no he dicho otra cosa que lo que estaba en la conciencia de los que presenciaron el fin trágico de la antigua legitimidad" (1900, p. XLVIII). Y aunque el texto de Cuenca carece de una presentación de este tipo (pues la edición que se conoce es un fragmento de un texto mayor), el autor inicia sus recuerdos de la guerra con un significativo "partía yo para el ejército" (1893, p. 145), afirmación que lo pondrá en el núcleo de las acciones que narra y que, a veces, somete al escrutinio crítico, como lo hacía al referirse a José María Obando (1795-1861), de quien decía: "No admiro a los hombres de su clase, siempre dispuestos a caer en los peligros de la adulación"; sin embargo, reconocía que hombres como aquel eran "una gran fuerza en estas democracias ignorantes que todo lo personalizan" (1893, p. 155).

Prima pues el carácter público-político del narrador, que impone su voz y su perspectiva ante la esfera pública; las memorias escritas en Colombia en el siglo XIX eran concebidas como una herramienta para justificar actuaciones, cuidar la honra, defenderse de los contradictores y elevar un nombre a la posteridad como ejemplo de virtud pública y cívica. Las memorias exaltaban el papel cumplido por los hombres de acción en la vida pública, quienes voluntariamente habían afrontado y decidido su destino. En consecuencia, no buscaban recuperar la voz de los seres anónimos, la gente del común que sufría en carne propia los estragos de la guerra, sino tomar como foco de interés el epicentro de las acciones en las que participó el narrador. En aquella época la noción de víctima difería considerablemente de la contemporánea, pues, la de víctima "pasiva", silente, parecía más un decorado de exaltaba las acciones del narrador, mientras que él se elevaba a una dimensión heroica, cuyo destino y sacrificios había aceptado voluntaria y conscientemente, al tiempo que establecía una analogía entre el discurrir de su vida y el de la República. Justamente 
por ello, las víctimas carecen de nombre y fisonomía y se las describe como una masa amorfa de cuerpos o de hombres y mujeres que sufrían en carne propia la guerra.

\section{Memorias y víctimas}

El propósito heroizante de las memorias, así como la preponderancia de las gestas y de los personajes que se identificaban con la República y con la moralidad cívica, hacían que las atrocidades y las víctimas de la guerra pasaran a un segundo plano. En comparación con la importancia de los jefes militares, pocas páginas se dedicaron a los horrores vividos por los reclutas, los campesinos o las mujeres en los campos de batalla, es decir, por los seres anónimos que, obligatoriamente, se veían inmersos en el torbellino de la guerra. Aunque cabe destacar que estas discusiones sí tuvieron lugar.

Tomás Cuenca describía la crudeza del combate con estas palabras: "[...] en pocos momentos el suelo estuvo cubierto de cadáveres y heridos; a los silbidos de las balas se unían los quejidos de los moribundos" (1893, p. 153). La víctima era un agente subsidiario que sufría en lugar de otro. En el siglo XIX esta noción seguía encorsetada en la religión, y con ella se hacía referencia a los hombres, la mayoría de ellos sin nombre, que pasivamente habían sufrido el destino impuesto por los hombres de acción. El contraste entre la pasividad sufriente y la actividad determinista ayudaba a dar mayor brillo a los hombres que, como los héroes trágicos, asumían el destino a costa de su vida. La actitud decidida de los hombres de acción se oponía a la de otros miles que, sacudidos por el torbellino de la guerra, eran reclutados forzosamente, expoliados y agredidos de todas las formas posibles. Las mujeres también eran víctimas: violadas y abandonadas unas, mientras contingentes femeninos seguían a los ejércitos y "como buitres se arrojaban sobre los cuerpos" (Cuervo, 1900, p. 56) de los oficiales muertos para desnudarlos.

Sin armamento ni bastimentos necesarios para la vida en campaña y sin entender muy bien las razones por las que debían luchar, agobiados por el hambre, el miedo y la enfermedad, muchos reclutas desertaban, aun conociendo las duras sanciones a las que 
se harían merecedores si eran atrapados. Entre ellas, la pena de muerte. Ángel Cuervo rememoraba así el ajusticiamiento de un desertor: "Infeliz criatura, víctima de nuestras pasiones políticas"; un joven honrado que sostenía a su madre, "un mozo inocente de vida ejemplar" (1900, p. 156) y que, en contravía del ideal heroico de la muerte en el combate, fue fusilado, degradado y deshonrado, para servir de escarmiento a los posibles desertores.

Mientras la noción de víctima adquiere hoy una connotación individual que tiene voz y expresa su experiencia traumática, en la época que nos ocupa la víctima solo existía a través de la voz de otros. La víctima se fusionaba en los horrores descritos en los campos de batalla o en las crueles marcas físicas que dejaban los combates en los cuerpos. Una frase de Tomás Cuenca nos deja una idea de la aterradora situación de quienes tenían que ver las atrocidades del combate: "[...] pedazos desgarrados del cuerpo humano se pisoteaban y machacaban como si fueran pedazos de leña” (1893, p. 156), hombres sin nombre, carentes de rasgos físicos, cuerpos estropeados cuya existencia quedaba borrada.

La individualidad se fundía aquí con el ideal social que quería propagarse. El estudio de los autodocumentos obliga en muchos casos a traspasar las pretensiones individuales para ubicarlas en un contexto social en el que ciertas singularidades se convierten en representaciones de un orden social deseado o despreciado. La individualidad heroica y la singularidad de algunas víctimas, nombradas y representadas con su identidad, era el rasgo de la historia magistra vitae, mediante la cual podía desplegar su función de educadora del porvenir. Uncida a la tradición hagiográfica, la imagen del mártir tuvo un lugar excepcional: entendido el martirio como la decisión personal de morir por una causa loable que trascendía la vida personal (Cardona, 2019, p. 311), los hombres caídos en la guerra se presentaban como "víctimas inmaculadas ofrecidas por la salvación de la República y en expiación de los desaciertos ajenos", según lo relataba Ángel Cuervo (1900, p. 121). Vistos como héroes o mártires, las individualidades fueron el vehículo para la enseñanza de valores absolutos que, por ello mismo, eran inmutables, incuestionables y verdaderos; frente a estas consideraciones, la imitación del heroísmo y 
las acciones loables era lo que justificaba intrínsecamente el pasado y su concreción en diversos textos escritos.

\section{Acciones de guerra y paz}

En el siglo XIX la guerra tenía tres escenarios principales: el de la diplomacia y la negociación, el del campo de batalla y el que se expandía a toda la sociedad como una fatalidad que envolvía a todos sus habitantes y obligaba a tomar partido por uno de los bandos. El reclutamiento forzoso, la expoliación, el robo y el pillaje eran acciones frecuentes en la guerra decimonónica, y ante la ausencia de contenciones jurídicas esta se extendía como guerra a muerte contra el adversario que debía ser eliminado.

Esa iusta causa (Schmitt, 2005, p. 121) debía ser combatida para convertir o aniquilar al enemigo radical, al que no se le reconocía derecho alguno. Este fue el concepto que dominó casi todas guerras del siglo XIX. En ellas, el derecho de gentes aparecía de modo singularizado y como iniciativa particular de algunos sujetos o grupos, asistemático e indefinido. En su ausencia las guerras difícilmente podrían regularse por medio de mecanismos ajenos a su propia dinámica o en temporalidades impuestas y no coincidentes con las mismas acciones militares. La mayoría de iniciativas de contención y limitación surgían de los campos de combate, y por ello, en la guerra de 1859, sus alcances fueron limitados, pues tales iniciativas se toparon con un muro levantado sobre los argumentos legales que impedían negociar una guerra desbordada en sus alcances y procederes. Carl Schmitt señala que el derecho de gentes relegó la iusta causa, basada en la autoridad de la Iglesia, y puso en primer plano al iustis hostis, al que se le reconoce como contraparte legítima en la guerra justa (2005, p. 110); de ese modo, el énfasis deja de estar puesto en la guerra en cuanto acción de exterminio del enemigo absoluto, y al tiempo que a este se lo relativiza y se le otorga legitimidad, se abren las vías a la negociación y la contención como elementos constitutivos de la guerra misma. De la guerra absoluta se pasa, entonces, a la guerra limitada por el derecho y como objeto de este. 
En sus informes al Congreso de la Confederación en 1861, el presidente Ospina describía la situación política de un país dividido y desangrado por un conjunto de "quebrados, jugadores, vagabundos de profesión, prófugos o indultados y gente perdida de todo género" (1861, p. 10), criminales que así deberían ser tratados. Basado en esta conjetura, equiparaba el indulto o la amnistía con la impunidad; el levantamiento en armas era entonces "un delito en todos los países del mundo" (p. 12) castigado severamente y los conspiradores sometidos a la ley penal sin consideraciones de ninguna clase, con lo cual se les negaba el estatuto de beligerancia como contraparte política de la guerra. Iván Orozco Abad (2006) explica el empeño criminalizante de Ospina como el resultado de una situación política y jurídica particular, pues, ante el abandono del discurso teológico de la república cristiana, las instituciones fundadas por las élites liberales solo podían tratar los conflictos armados internos como delitos y, consecuentemente, se imponían las prácticas punitivas (bellum punitivum) (2006, p. 110) por parte del gobierno y, con ellas, el desbordamiento de la violencia que, a la sazón, equiparaba la justicia con la venganza y la retaliación. Las prácticas de negociación localizadas espacial y temporalmente eran entonces una manera de suturar la brecha entre la criminalización de los levantamientos armados contra el gobierno de turno y su reconocimiento como parte política de la contienda.

De forma paulatina, y no exenta de discusiones y opositores, el derecho de gentes y la contención de la guerra fueron cobrando relevancia y las estrategias y prácticas se hicieron cada vez más recurrentes. De hecho, las memorias que aquí analizamos tienen dos características relacionadas con este punto; la primera es que, pese a participar activamente en la guerra, ambos autores asumieron en sus textos posturas críticas frente a la guerra total y a la falta de planeación de los combates, que los hacía más crueles y mortíferos. La segunda consiste, precisamente, en la descripción de esa crueldad; "al hambre, a la deserción, se agregaban otros males: la quebrada que cruzaba el campamento estaba envenenada por los cadáveres en putrefacción [...]”, escribe Tomás Cuenca sobre la dura situación del ejército federal (1893, p. 156), mientras Ángel Cuervo recordaba los 
"cadáveres insepultos", los "heridos arrastrándose por las charcas de sangre; los sanos con sed y sin poder saciarla, pues el arroyo que pasaba junto estaba lleno de hombres y de caballos muertos" (1900, p. 158).

En estos autores las descripciones sobre la brutalidad de los combates y la precaria situación de los combatientes refleja una preocupación frente a las desgracias de la guerra, pues si bien la retórica de exaltación de la valentía en el combate seguía vigente, el interés por los efectos colaterales de la conflagración y las descripciones sobre muertos, heridos y combates demostraban una inquietud creciente por la situación cotidiana de las huestes y por la inutilidad de la lucha a muerte. Ciertamente, en la guerra de 1859-1862 se desplegaron varias estrategias que fueron el preludio de las discusiones que se dieron en la Convención de 1863 y que culminaron con la inclusión del artículo 91 sobre la incorporación del derecho de gentes como principio de rango constitucional ese mismo año. ${ }^{3}$

El camino fue lento y tortuoso; la nefasta guerra de 1859 fue objeto de discusiones y puntos de vista diversos. El gobierno de Mariano Ospina fue renuente a aceptar cualquier negociación que implicara reconocer la condición de beligerancia a las huestes levantadas contra el gobierno; aducía que las leyes no "lo facultaban para las negociaciones" (Parra, 1912, p. 307), sino para restablecer el orden mediante el castigo a los rebeldes. Apelaba a la justicia de Dios "para poder dar término a las depredaciones e iniquidades de los traidores"; solo el fervor y la oración de los ciudadanos atraerían el castigo divino a las "hordas feroces" (Cuervo, 1900, p. 208). Con este lenguaje cargado de animadversión y de términos que representaban

\footnotetext{
"El Derecho de gentes hace parte de la Legislación nacional. Sus disposiciones regirán especialmente en los casos de guerra civil. En consecuencia, puede ponerse término a ésta por medio de Tratados entre los beligerantes, quienes deberán respetar las prácticas humanitarias de las naciones cristianas y civilizadas" (Constitución Política de los Estados Unidos de Colombia, 1871, Art. 91, p. 35). Es pertinente citar, respecto a la trascendencia del artículo 91, las palabras del constitucionalista Carlos Restrepo Piedrahíta en una carta dirigida al director del periódico El Tiempo el primero de septiembre de 1994: "Fue la Constitución radical de 1863 la primera que en el mundo dispuso la incorporación del Derecho de Gentes -para fines humanitarios- en el ordenamiento interno de los Estados Unidos de Colombia [...] Concordante fue el numeral 15 del artículo 17 que prescribió como atribución del gobierno general de la Unión proveer la legislación judicial y penal en los casos de violación del Derecho Internacional” (Restrepo, 1994, párr. 1).
} 
al enemigo como una banda de malhechores salvajes que el gobierno debía aniquilar, los partidarios del gobierno central justificaban su posición punitiva contra "los reos que con las armas en la mano resisten a la autoridad pública, por escapar a su juzgamiento legal y que oprimen y devastan a los pueblos" (Ospina, 1861, p. 10).

En actitud crítica frente a la satanización del adversario y el tratamiento punitivo de los alzados en armas, Pedro Alcántara Herrán (1800-1872) hizo un llamado a la condescendencia del gobierno legítimo para resolver una guerra sin salida y cada vez más degradada. Le recordaba al presidente Ospina que entre las filas de los revolucionarios militaban tres expresidentes (José Antonio Obando, José Hilario López y Tomás Cipriano de Mosquera), que eran lo suficientemente poderosos como para imponer condiciones de paz y que "no porque se le llama cuadrilla de bandidos deja de tener ese poder" (Herrán, 1901, p. 81). En concordancia con este argumento, proponía más bien evitar el trato punitivo que, presentado como justicia, era invocado por los partidos "para exterminar al otro" (1901, p. 83). La justicia penal con castigos proporcionales a las culpas era la única posibilidad de lograr el cese de la guerra y la conciliación entre las partes.

La línea divisoria entre una revuelta de facinerosos y una revolución política liderada por fuerzas beligerantes estaba marcada por el tratamiento político que confería la nominación de guerra civil al enfrentamiento entre ejércitos reconocidos y sometidos al derecho; así, la incorporación del derecho de gentes supuso también ampliar las posibilidades de maniobra política para reglamentar, controlar y superar la guerra, y, aún más importante, generar los mecanismos necesarios para la reincorporación de los actores y su inserción social y política. En efecto, nociones como perdón y olvido están contenidas en figuras como las del indulto y la amnistía, las cuales remiten, a su vez, a la clemencia en cuanto favor o don que se concede a quien ha desviado su camino: al olvido total por la ofensa recibida, o al perdón a quien ya ha recibido una pena por causa de sus acciones erráticas, lo cual favoreció el tránsito hacia la paz y la integración de muchos líderes militares a las actividades políticas, pero también su rápida reconversión militar en nuevas guerras civiles. 
La amnistía, dice Paul Ricœur (2004, pp. 577-581), está vinculada con la memoria y el olvido. La amnistía se define como el olvido selectivo sobre ciertas acciones que es preciso borrar para poder continuar. La amnistía omite los procesos y diligencias jurídicas que imponen castigos sobre los delitos cometidos durante una conflagración; acuerdos, pactos y negociaciones pasan a ser una instancia que se impone a la justicia "que mantiene los conflictos con el pretexto de resolverlos" (Ricœur, 2004, p. 579). Esto hace palpable la tensión entre la administración institucional del olvido, refrendada en la amnistía, y la reivindicación de la memoria por parte de la justicia mediante la vía de la sanción y la gestión del castigo. La amnistía pues, es un olvido institucional que supone la administración de la memoria, de aquello que es preciso olvidar para mantener vigente el pacto social. La administración del olvido implica, también, el fortalecimiento de un relato que cumple el papel de recuerdo que hace posible la reconciliación y, "entre ciudadanos enemigos, la paz cívica” (Ricœur, 2004, p. 578).

\section{La paz y el progreso}

A pesar de que la noción primaria de paz se fundamentaba en la teología agustiniana (que la definía como un bien absoluto en la ciudad de Dios y como un bien incierto en la ciudad terrena; este bien se comprendía como la ausencia de disenso, la disposición de las cosas semejantes y la subordinación al lugar asignado por Dios a cada uno; además de la unidad del corazón o concordia que mantiene el amor entre los hombres y entre estos y su creador; Agustín, XIX, 13), en las memorias estudiadas se evidencia un desplazamiento hacia definiciones y explicaciones mucho más concretas, antes que proveer enunciaciones en abstracto o especulaciones metafísicas. Partiendo de la definición de paz como "tranquilidad en el orden", Rufino Cuervo, prologuista de su hermano Ángel en el libro Cómo se evapora un ejército, aseveraba que la "prosperidad" le era inherente a la paz, y esa conjunción solo sería posible por medio del "desarrollo armónico de varias fuerzas de la nación” (1900, p. LIII). El trabajo material, la incorporación de sencillas tecnologías para mejorar la 
producción a la que estaban acostumbrados los habitantes del país, el comercio, solo serían posibles cuando se implementaran los medios para mantener la armonía y la tranquilidad, condiciones sine qua non para el progreso. Para Ángel Cuervo y, en general, para los miembros más importantes del partido conservador, la paz era el despliegue de los principios liberales: el respeto a todos los derechos y todas las garantías, "dejando a las libertades de todo género explayarse sin obstáculo en el ancho campo de la ley" (1900, p. 78).

Para demostrar los beneficios prácticos de la paz, Ángel Cuervo recordaba en su relato, con cierto idealismo, los efectos del golpe de José María Melo y "la dictadura de 1854", que había propiciado un período de armonía y estabilidad política que se reflejó en el desarrollo económico y en una interesante actividad intelectual. Los partidos se unificaron en pos de la derrota de un enemigo común: el golpe de Melo produjo la "reconciliación" de los partidos para defender la Constitución, y con ella "el imperio de la Justicia" (iusta causa). La reconciliación entre dos partidos opuestos, originada por un enemigo común, cobijó con la misma bandera a sus principales caudillos, lo que instaló, en palabras del escritor, "la unión de la familia granadina", una fratria unida por intereses superiores y no por el prurito ideológico y faccioso. Este halagüeño panorama tuvo su máxima expresión en el gobierno (1855-1857) de Manuel María Mallarino (1802-1872), que consiguió mantener los pactos surgidos de los campos de batalla y posibilitó un gobierno bipartidista que, confiado en los avenimientos, entregó "a la nación misma el sostenimiento del orden y de la ley" (Cuervo, 1900, p. 3).

Gracias a la armonía y al sentimiento de fraternidad reinantes, el gobierno de Mallarino redujo el ejército "a 400 hombres” destinándolo a custodiar los parques y los presidios. La reducción y la destinación del ejército demostraban el desprecio que en esos tiempos pacíficos se sentía por la milicia, considerándola una "institución anticuada e impropia de las ideas modernas” (Cuervo, 1900, p. 3). En compensación, las letras afloraron con asociaciones y publicaciones que defendían la existencia de una comunidad de hombres, unidos por la poesía y el saber, cuyas solidaridades permitían la formación de una verdadera república de las letras, en la que las barreras partidistas eran reemplazadas por la 
caballerosidad y el deseo de educar y servir a la patria. Para conjurar la guerra y erradicarla completamente del país, Ángel Cuervo recordaba que el gobierno tomó la decisión de desartillar las murallas de Cartagena y "por un pan se vendieron cañones monumentales" (1900, p. 7). Cuervo entendía la paz no como el silencio absoluto de las armas; su concepción era más pragmática y con efectos sociales, como un acuerdo fraternal entre partes antiguamente hostiles que, gracias a los pactos, permitieran deponer los intereses partidistas por un fin mayor: el progreso económico y moral de la República, el afianzamiento de la industria y el comercio y el desarrollo intelectual que haría posible el bienestar de todos sus habitantes.

Por su parte, Tomás Cuenca detalla los horrores de la guerra en la mísera situación de los militantes y en el triste abandono de los heridos y de los cadáveres en los campos de batalla. En sus memorias, la paz tiene una dimensión mucho más concernida a los avenimientos entre los líderes de los bandos enfrentados y a la solución inmediata de las causales de la guerra, que a una disertación filosófica o política a largo plazo. Justamente, en medio de una conflagración cruel y sangrienta, Cuenca reflexionaba sobre lo que significa la guerra como conculcación de todos los derechos y comisión de todos los delitos en nombre de una causa que no era en sí misma buena (iusta causa). La guerra es, por lo tanto, un borramiento total de todos los principios liberales: ni la libertad, ni la propiedad, ni la moralidad, ni la civilidad quedaban incólumes a su paso; en su lugar, decía Cuenca, "quedan la expropiación, el empréstito, el recluta y el prisionero" (1879, p. 148). Con la guerra se perdían los escrúpulos que reinaban en tiempos de paz, en nombre de diversas causas, y acciones deshonrosas pasaban a convertirse en práctica recurrente y legítima: robos, saqueos, vejámenes de todo tipo se convertían en una forma de disuasión, de tal suerte que los vicios "ocupan el lugar que deja el vacío moral" (p. 148).

En el ejército, el derecho era reemplazado por la fuerza para evitar el relajamiento de la disciplina y la desobediencia; las escasas ideas de comunidad y civilidad naufragaban en ese régimen. Esta desoladora situación llevaba a cavilar sobre si era posible que de este mal brotara algún bien, lo que dejaba entrever la necesidad de defender 
los derechos del hombre contra los embates del personalismo que tendía a cercenarlos. La catastrófica situación de la guerra llevaba a Cuenca a resaltar los beneficios de la paz, "sustituyendo con los combates humanitarios de la diplomacia" el ruido de los fusiles y la crueldad de los hombres en los campos de batalla. Así, su idea de paz era más objetiva y a corto plazo: la negociación entre los bandos, la defensa de los principios que habían movilizado a los liberales radicales, así como los acuerdos que mermaban el sufrimiento de los combatientes: "[...] establecer hospitales para atender a los heridos, permitir el enterramiento de cadáveres, menguar el sufrimiento de las víctimas" (Cuenca, 1879, p. 150).

Pero los acuerdos no eran necesariamente buenos, ni producían por sí mismos la contención y la felicidad que pretendían sus firmantes; antes bien, sostenía Cuenca, el armisticio de la quebrada de Chaguaní había tenido un efecto nefasto pues, antes que parar la guerra, había sido el acicate de las sangrientas batallas que vinieron después, con un aterrador resultado de muerte y desolación. Cuenca relativizaba el "pensamiento humanitario" que sustentaba el Armisticio de Chaguaní, ya que según su criterio este no había dado solución a la guerra, sino que la había prolongado; sin el armisticio, decía, "se habrían evitado los combates de Tunja, Usaquén, Bogotá, Neiva, y la Manga, los del Cauca, etc." (Cuenca, 1879, p. 151).

La guerra podría ser inevitable "porque representa el estallido de los malos instintos que la especie trae consigo" (Cuenca, 1879, p. 154), pero no era necesaria. La paz era el resultado de acuerdos humanitarios que reducían los horrores de la guerra, pero era también la extensión del Derecho, la propiedad privada y la libertad. No se trataba entonces de un estado de armonía opuesto a la guerra, sino más bien del producto de acciones concretas, acuerdos e implementación de derechos y libertades, derivados, para infortunio de los hombres, de la guerra. Tanto la paz como la guerra eran el resultado de tensiones, transformaciones y acciones específicas móviles y dinámicas que producían alternancias y frágiles equilibrios entre poderes enfrentados. 


\section{A modo de conclusión}

La guerra de 1860 fue, quizá, en la que más impacto tuvieron las prácticas de negociación temporal y territorial de la lucha. Varias razones pueden justificar este hecho, pero destacamos dos: la primera es que la desmembración del Estado del Cauca de la Confederación obligaba a Mosquera a desarrollar mecanismos que permitieran el tránsito de una revuelta regional a una guerra civil con visos internacionales, en la que además de jefe militar, Mosquera adquiriera la connotación de un jefe político internacional y, por ende, la de parte negociadora legítima. La segunda es la brutalidad de la guerra, así como la falta de previsión, preparación y contención por parte del gobierno central, que se negaba sistemáticamente a reconocer el estatus de beligerancia de los ejércitos sublevados, a quienes llamaba "hordas negras, caribes y salvajes", con quienes no se debía dialogar; con ellos era necesario "el vigor y la represión, la severidad de las penas, la justicia práctica” (Justus, 1860, p. 2), lo que paradójicamente incentivó las negociaciones de los jefes militares, en procura de aminorar las pérdidas y planificar mejor las operaciones.

Las memorias de Ángel Cuervo y Tomás Cuenca son documentos que, contrastados, permiten entender las dinámicas de la guerra y la paz como realidades correlacionadas e imbricadas que, más allá de disertaciones filosóficas o definiciones absolutas, suponían acciones concretas, territorial y temporalmente acotadas, con resultados evidentes a corto plazo como la posibilidad de recoger a los muertos y atender a los heridos, con alcances limitados y concernidos. No obstante, estas estrategias acotadas permitieron recorrer el camino hacia la regularización de la guerra y la comprensión de la paz como una instancia jurídica de regulación y tramitación de la contrariedad política. La paz empezó a deslindarse del discurso religioso que la circunscribía al mantenimiento de la gracia divina con la obediencia y la sujeción al orden sagrado, para transitar hacia un plano más mundano. Allí, más que un concepto absoluto, pasó a definirse a través de acciones concretas y evidencias sociales. La paz se convirtió en correlato de progreso y crecimiento económico, del ejercicio de la ciudadanía, del despliegue de derechos como la libertad, la igualdad 
y la democracia. Ángel Cuervo y Tomás Cuenca vivieron en carne propia las atrocidades de la guerra, y también presenciaron las iniciativas para frenar en momentos, lugares y situaciones precisas, sus efectos $\mathbf{I}$

\section{Referencias}

Actos oficiales del gobierno provisorio de los Estados Unidos de Colombia, recopilados conforme a lo dispuesto por el Decreto del 7 de abril de 1862. (1862). Imprenta de Echavarría Hermanos. [Biblioteca Nacional de Colombia, Fondo Vergara 261].

Aguilera Peña, M. (2012). Refundemos la nación: perdonemos a los delincuentes políticos y comunes. Análisis Político, 25(76), 5-40. https://revistas.unal.edu.co/index.php/anpol/article/view/43493/44768.

Agustín (s. f.). Libro XIX, Cap. XIII. Fines de las Ciudades. En La ciudad de Dios (pp. 598-599). Libros Clásicos.org. https://bit.ly/3rYBQXM.

Cardona Z., P. (2019). El pasado como modelo a imitar. Relaciones entre historia y memorias, siglo xIX colombiano. Co-herencia, 16(31), 291319. https://doi.org/10.17230/co-herencia.16.31.9.

Constitución Política de los Estados Unidos de Colombia, sancionada el 8 de mayo de 1863. (1871). [Edición oficial revisada por una comisión de la Cámara de Representantes, compuesta por un miembro de cada Estado]. Imprenta i estereotipia de Medardo Rivas. [Sala de Patrimonio Documental Biblioteca Luis Echavarría Villegas, Universidad EAFIT]. https://bit.ly/32mFJMP.

Cuenca, T. (1893). Notas sobre la campaña de 1861 y pensamientos (Jorge Roa, pról.). Imprenta de la Luz. [Biblioteca Nacional de Colombia, Fondo Cuervo 1379, pieza 11].

Cuervo, Á. (1900). Cómo se evapora un ejército: Recuerdos personales de la campaña que concluyó el 18 de julio de 1861 con la toma de Bogotá por los revolucionarios. Imprenta de Durand. [Biblioteca Nacional de Colombia, Fondo Cuervo, 3796].

Garrido M., Gutiérrez A. D. y Camacho A. C. (2018). La paz en la República: Colombia, siglo xIx. Universidad Externado de Colombia. 
Guerrero Apráez, V. (2016). Guerras civiles en Colombia. Negociación, regulación y memoria. Pontifica Universidad Javeriana.

Guerrero Apráez, V. (2017). El reconocimiento de la beligerancia. Dos siglos de negociaciones y salida negociada de los conflictos armados. Pontifica Universidad Javeriana.

Herrán, P. A. (1901). Política de conciliación. Librería Nueva. [Biblioteca Nacional de Colombia, Miscelánea 489, pieza 13].

Justus. (1860, diciembre 4). Al Señor José María Vergara y Vergara, redactor de El Heraldo [sin pie de imprenta]. [Biblioteca Nacional de Colombia, Fondo Pineda 224, pieza 16].

Karl, R. A. (2018). La paz olvidada: Políticos, letrados, campesinos y el surgimiento de las FARC en la formación de la Colombia contemporánea. Librería Lerner.

Koselleck, R. (2004). historia/Historia. Trotta.

Ospina, M. (1861). Informe del presidente de la Confederación Granadina al congreso Nacional de 1861. Imprenta de la Nación. [Biblioteca Nacional de Colombia, Fondo Pineda, 369, pieza 6].

Orozco Abad, I. (2006). Combatientes, guerreros y terroristas, 2. a ed. Temis. Parra, A. (1912). Memorias de Aquileo Parra, presidente de Colombia de 1876 a 1876 (comprenden de 1825 a 1876). Imprenta de La luz, Librería colombiana.

Posada Gutiérrez, J. (1975). Memorias histórico políticas Tomo III. Bedout.

Restrepo Piedrahíta, C. (1994, septiembre 1). Derecho de Gentes. El Tiempo.com. https://bit.ly/2B6fYFn

Ricœur, P. (2004). La memoria, la historia, el olvido. Fondo de Cultura Económica.

Rivera Páez, S. (2019). Militares e identidad: Autorrepresentación y construcción de paz en el cuerpo de oficiales de las Fuerzas Militares colombianas. Pontifica Universidad Javeriana.

Schmitt, C. (2005). El nomos de la tierra. El derecho de gentes del "Jus publicum europeaum". Struthart.

Uribe de H., M. T. (2003). Las guerras civiles y la negociación política: 
Colombia, primera mitad del siglo xIx. Revista de Estudios Sociales, (16), 29-41. https://doi.org/10.7440/res16.2003.03.

Uribe de Hincapié, M. T. y López Lopera, L. (2006). Las palabras de la guerra: Un estudio sobre las memorias de las guerras civiles en Colombia. La Carreta Editores.

Uribe de Hincapié, M. T. y López Lopera, L. (2008). La guerra por las Soberanías: Memorias y relatos en la guerra civil de 1859-1862 en Colombia. La Carreta Editores.

Vitoria, F. de (2008). Relectio de potestate civili: estudios sobre su filosofía política (Edición crítica de J. Cordero Pando). Consejo Superior de Investigaciones Científicas. 